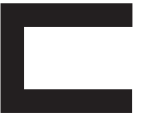

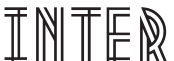

\title{
PLURALIDADE FAMILIAR CONTEMPORÂNEA E PRÁTICAS EDUCATIVAS PARENTAIS: O QUE A LITERATURA TEM A DIZER
}

Cláudia Paranhos de Jesus Portela ${ }^{1}$

\section{RESUMO}

A contemporaneidade tem provocado mudanças estruturais no panorama social. Dentre essas mudanças está a diversificação dos modos de vida familiar onde o modelo de família tradicional tem cedido lugar para o aparecimento de outros. 0 eixo de discussão deste estudo direciona-se para analisar a influência dessa onda de transformações por qual vem passando $a(s)$ família(s) no que diz respeito às práti- cas educativas parentais e sua relação com a escola dos filhos. A análise será embasa nos pressupostos teóricos da Teoria da Reprodução.

\section{PALAVRAS-CHAVE}

Configurações Familiares. Práticas Educativas. Relação Família-Escola. 


\section{ABSTRACT}

Contemporaneity has caused structural changes in the social landscape. Among these changes is the diversification of modes of family life where the traditional family model has given place to the appearance of others. The axis of discussion of this study directs is directed to analyze the influence of this wave of transformations because it comes through the family(s) with regard to parental educational

\section{RESUMEN}

La contemporaneidad ha provocado cambios estructurales en el panorama social. Entre estos cambios se incluyen la diversificación de los modos de vida familiar donde el modelo tradicional de familia ha dado lugar a la aparición de otros. El eje de la discusión de este estudio dirige a sí mismo para analizar la influencia de esta ola de transformaciones porque viene a través de la familia (s) con respecto practices and their relationship to school of children. The analysis will be bases on theoretical assumptions of the Theory of Reproduction.

\section{KEYWORDS}

Family Configurations. Educational Practices. Family-School Relationship.

a las prácticas educativas parentales y su relación a niños en edad escolar. El análisis será basado en supuestos teóricos de la Teoría de la Reproducción.

\section{PALABRAS-CLAVE}

Valores familiares. Prácticas educativas. Relación familia escuela. 


\section{INTRODUCÃO}

A contemporaneidade tem provocado mudanças estruturais no panorama social. Dentre essas mudanças está a diversificação dos modos de vida familiar onde o modelo de família tradicional tem cedido lugar para o aparecimento de outros. A literatura especializada sobre família tem ressaltado muitas particularidades relacionadas aos arranjos e formas contemporâneas de vida familiar. No entanto, muito pouco, ou quase nada, se falou até agora sobre a dinâmica das práticas educativas dos pais.

0 eixo de discussão, pois, deste estudo direciona-se para analisar a influência dessa onda de transformações porque vem passando a(s) família(s) no que diz respeito às práticas educativas parentais e sua relação com a escola dos filhos, a qual apesar de inicialmente demonstrar ser somente uma discussão de conteúdos escolares, tem por trás uma complexidade de relações culturais, sociais e ideológicas implicando conflitos entre os atores envolvidos. Tal análise será embasa nos pressupostos teóricos da Teoria da Reprodução.

\section{A LITERATURA SOBRE A TEMÁTICA: CONFLITOS E QUESTÕES ATUAIS}

Falar de família nesse início de século significa referir-se a um fato em "desordem" tendo em vista que seus indicadores de ordem desfizeram-se a tal ponto que dificultam determinar com nitidez o que a delimita.

[...] Vive-se uma época, como nenhuma outra, em que a mais naturalizada de todas as esferas sociais, a família, além de sofrer importantes abalos internos, tem sido alvo de importantes interferências externas. Estas dificultam sustentar a ideologia que associa a família à idéia de natureza, ao evidenciarem que os acontecimentos na família vão além de respostas biológicas universais às necessidades humanas, mas configuram diferentes respostas sociais e culturais, disponíveis a homens e mulheres em contextos históricos específicos. (SARTI, 2004 p. 194).

Assim, a família enquanto instituição social compartilha das transformações próprias das relações sociais, sofrendo dessa forma as influências do contexto político, econômico e cultural no qual se encontra inserida. "A família é, por um lado, um fenômeno fundado na natureza própria do homem e, por outro, uma instituição social, e como tal, varia através da história e de uma cultura para outra" (WAGNER, 2002, p. 9)

As transformações nos comportamentos demográficos depois dos anos 1960, segundo François de Singly (2007), repercutiram de variados modos na organização dos modos de vida familiar dos indivíduos e de suas relações. Os indicadores demográficos responsáveis por essas transformações podem ser aqui resumidos: diminuição do número de casamentos e recasamentos e o aumento das uniões livres; o crescimento do divórcio; a redução da natalidade; o aumento do número de nascimentos fora do casamento; a ampliação do trabalho assalariado das mulheres, principalmente das mães.

Com isso, a família encontra-se, em constante transformação, por participar dos dinamismos próprios das relações sociais. Assim, agregada ao processo social, ela passa, então, por mudanças significativas. Em meio às alterações sociais e culturais, a família esforça-se para organizar aspectos inerentes a si que o contexto sociocultural vai modificando. Enfrentando os fatores externos e, ao mesmo tempo, procurando readaptar-se a eles, a família segue então, buscando novas formas de organização, dando continuidade ao ciclo evolutivo que atravessa ao longo da sua existência. De tal modo, a família contemporânea tem se caracterizado por uma grande variedade de formas, que documentam a inadequação dos vários modelos da tradição.

\footnotetext{
O modelo tradicional de família, composta por pai, mãe e filhos, está sofrendo grandes modificações, as quais têm alterado tanto a sua configuração como o seu funcionamento. As mudanças, assim, se expressam não somente na composição da família, mas também nos papéis desempenhados pelos seus membros no seio da família. (GRZYBOWSKI, 2002, p. 39).
} 
O divórcio ${ }^{2}$ tem sido apontado como um dos fatores que têm favorecido para a ocorrência de modificações na estrutura e funcionamento da família, fazendo nascer novos arranjos familiares, os quais se distanciam daqueles que vigoraram no passado. Isso se justifica pelo fato do mesmo demandar mudanças, a quais normalmente irá solicitar uma nova organização familiar.

Desde sua aprovação no Brasil (1977), o número de divórcios tem aumentado muito; em dez anos, quase que dobrou, atingindo, nos dias atuais, a 200.000 por ano, o que representa um divórcio em cada quatro casamentos. Além disso, há uma previsão de que, em apenas duas décadas, o número de famílias nucleares tradicionais de um primeiro casamento será menor que o de novas uniões resultantes de separações e divórcios. Isso significa dizer que, de cada cinco bebês que estão nascendo neste ano, um viverá em famílias de pais separados antes de atingir a vida adulta. (GRANATO; DI MARI apud WAGNER 2002, p. 41).

Portanto, pode-se perceber que as transformações operadas na família estão ligadas ao número, cada vez mais crescente, de disrupções conjugais mediante as separações e divórcios, como mostra o Gráfico a seguir:

GRÁFICO 1 - Taxa de crescimento das pessoas de 15 anos ou mais de idade, segundo o estado conjugal, entre 1970 e 1995
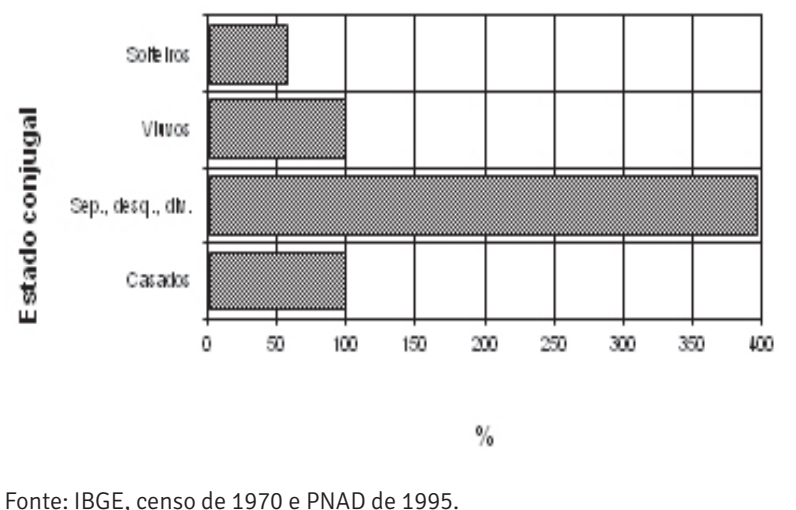

2. Segundo Grzybowski (2002, p. 40), “o divórcio se constitui como uma crise inesperada do ciclo evolutivo vital familiar”.
Associado a isso o Instituto Brasileiro de Geografia e Estatística (IBGE) registrou um rejuvenescimento da população divorciada, sendo que um equivalente a $51,0 \%$ tinha menos de 40 anos em 1995, contrariamente a $44,2 \%$ no ano de $1970^{3}$. Esse fato evidencia que, diante do número de pessoas divorciadas ou separadas com potencial de casarem novamente é grande, visto que estão jovens. E, como afirmam vários estudos sobre o assunto, as chances dos ex-cônjuges refazerem suas relações conjugais estão relacionadas diretamente à precocidade com que encerram a primeira relação. Esses indicadores justificam claramente a razão porque o número de casamentos que envolve ao menos um parceiro divorciado tem evoluído continuamente, ao contrário do número de casamentos entre solteiros, que em 1990 teve um total de 724.753, e em 2002, um quantitativo de $619.830^{4}$, o que equivale a um decréscimo de $14,83 \%$, considerando que desde a década anterior, esse número vem diminuindo progressivamente, como mostra a Tabela abaixo:

Tabela 1 - Casamento entre solteiros

\section{CASAMENTOS ENTRE SOLTEIROS (UNIDADES)}

\begin{tabular}{|ll|}
\hline 1990 & 727.753 \\
\hline 1991 & 692.112 \\
\hline 1992 & 693.969 \\
\hline 1993 & 688.811 \\
\hline 1994 & 700.162 \\
\hline 1995 & 699.267 \\
\hline 1996 & 665.556 \\
\hline 1997 & 653.188 \\
\hline 1998 & 626.984 \\
\hline 2001 & 622.574 \\
\hline 2002 & 619.830 \\
\hline Fonte: Dados do Registro Civil.
\end{tabular}

3. Fonte: Censo demográfico 1970 e PNAD 1995.

4. Fonte: Dados da Estatística de Registro Civil 2002. 
Também, destaca-se que entre os anos de 2002 e 2003 houve um aumento no número de casamento entre solteiros equivalente a $4,82 \%^{5}$, enquanto que em 2003, a diferença entre o número de casamentos entre solteiros para os demais casamentos foi de $13,05 \%{ }^{6}$. Esses dados mostram um pequeno crescimento no número de casamentos entre solteiros e um forte aumento nos casamentos em que, no mínimo, um dos cônjuges já teve uma união anterior.

Paralelo a isso, em 2003, o percentual das pessoas divorciadas ou separadas judicialmente com crianças menores, cujos pais têm até 44 anos de idade, corresponde a $27,78 \%{ }^{7}$, sendo que sua custódia fica resguardada a um ou a outro genitor. Ademais, considerando as probabilidades estatísticas apresentadas, de essas pessoas constituírem uma nova relação, do tipo recomposta e, os cônjuges não sendo infecundos, estes por sua vez, darão origem a novos filhos que consequentemente, irão conviver e se relacionar com os chamados meio-irmãos.

Esses dados são confirmados por Caster e McGoldrick (1995, p. 347), ao dizer que: "cerca de metade dos casais que casam pela segunda vez tem filhos, e a média estatística é a de que os casais que se divorciam e recasam o fazem num período de dez anos a partir do primeiro casamento". Dessa maneira, fica evidente que a família nuclear constitui-se cada vez menos no único ambiente de socialização das crianças.

Convém lembrar, entretanto, que os atores envolvidos nessa nova relação convivem, muitas vezes, com a ausência de prescrições sociais de papel para orientá-los, o que favorece para a não definição de condutas no âmbito dos diversos arranjos familiares. Nesse contexto, estão inseridas as condutas educativas.

5. Fonte: IBGE, Estatística de Registro Civil 2002 e 2003.

6. Fonte: IBGE Estatística de Registro Civil 2003.

7. Fonte: IBGE Estatística de Registro Civil 2003.
Diante disso, "a nossa sociedade de finais do século XX, caracteriza-se pela pluralidade dos modelos de conjugalidade, que tornam a definição da família crescentemente complexa" (SEGALEN, 1996, p. 165)

Nesse contexto, pode-se afirmar que o prognóstico do término da família, como núcleo responsável pela promoção do desenvolvimento e bem-estar dos seus membros, não se tornou realidade. Hoje, mais do que nunca, multiplicam-se as diferentes formas de organização familiar, assim, como as pesquisas interessadas em conhecer estes novos arranjos e suas potencialidades para promover e facilitar a saúde de seus membros. (WAGNER 2002, p. 24).

A título de exemplo têm-se além das famílias originadas de recasamentos, o elevado número de pessoas que preferem viver sozinhas, casais que vivem juntos sem estar casados oficialmente, ou seja, optam pela união consensual, netos sendo criados pelos avós, casais de homossexuais, pais que dividem a guarda dos filhos, pais com guarda conjunta, mães e pais divorciados, solteiros, viúvos, separados ou adotivos.

Essas transformações possibilitaram para que um novo cenário da vida familiar fosse configurado paulatinamente, com orientações específicas em cada sociedade, em cada país. Contudo, o que não sofreu interferência nesse contexto de transformações foi o fato da família, nas suas relações intrafamiliares, manter a construção identitária dos seus membros.

No bojo dessas transformações emergem novos valores educacionais. A título de exemplo, pode-se verificar que a educação familiar sofreu modificações menosprezando a obediência e aquilatando a iniciativa e a autonomia. Também, nesse contexto, estão inseridas as condutas educativas, ou seja, as práticas educativas dos pais.

Vale destacar que as práticas educativas não são um fenômeno isolado e, por isso, as mudanças ocorridas no seio da família, trazem, também, mudanças na forma de socializar e conduzir a educação das crian- 
ças, como também na maneira de se relacionar com a escola. Dessa forma, ao analisar as práticas educativas nas famílias é preciso tomar em conta que estas se constituem em "unidades dinâmicas de relações sociais” (BRUSCHINI, 1993).

Na conjuntura das práticas educativas dos pais, está a relação que estabelecem com a escola dos filhos, porque entre os fatores que exercem influência educativa na formação da personalidade do indivíduo, a família e a escola ocupam um lugar imprescindível e indissociável. Contudo, esta apesar de inicialmente demonstrar ser somente uma discussão de conteúdos escolares, tem por trás uma complexidade de relações culturais, sociais e ideológicas implicando conflitos entre os atores envolvidos. Destaca-se, assim, o que escreve Nogueira, Romanelli e Zago (2000, p. 10) sobre a questão:

[...] existe um relativo consenso, entre os autores, de que se trata de uma relação complexa, e, por vezes, assimétrica, no que diz respeito aos valores e objetivos entre as duas instituições, relação essa sujeita a conflitos de diferentes ordens, em especial nos bairros marcados por condições socioeconômicas desfavoráveis.

A referida complexidade tem seu fundamento no fato de a escola pleitear, junto à família, suas funções educativas. Esse fato tem sido claramente demonstrado em pesquisas que retratam o percurso histórico de substituição da família pela instituição escolar.

Tal é, por exemplo, o resultado apresentado pelos estudos de Marini e Mello, da Universidade Federal de São Carlos (2000, p. 7), sobre as relações entre a escola e as famílias de classes populares. As pesquisadoras constataram que:

[...] a escola age de forma preconceituosa com as crianças de classes populares, uma vez que julga a elas e a suas famílias a partir da proximidade ou não do padrão dominante de modelo de família conjugal nuclear e de infância, dentre tantos outros, e não procura ouvi-las. As relações entre o eu e o outro (enquanto grupos, classes, etc.) são estabelecidas com base na idéia de superioridade de um padrão sobre muitos outros e justificadas pela boa intenção de 'elevar' o outro ao padrão superior. (Grifos das autoras).

Percebe-se que, ao não conceber os indivíduos, suas formas de vida, seus motivos e suas concepções como legítimos, a escola deixa de notar as diferenças existentes entre o eu e o outro, eximindo-se, assim, de dialogar com quem a frequenta. Nesse aspecto, cabe aqui considerar a interdependência entre as condições sociais de origem dos pais de crianças e as formas de relação que estabelecem com a escola, uma vez que a família e a escola não podem ser consideradas abstratamente, ou seja, dissociadas de suas condições históricas e socioculturais. Segundo a Teoria Sócio-Histórico-Cultural, “[...] o homem constitui-se como tal através de suas interações sociais, portanto é visto como alguém que transforma e é transformado nas relações produzidas em uma determinada cultura” (REGO, 1995, p. 93).

Registra-se, na literatura, um consenso de vários estudiosos quanto à influência exercida pelas condições sociais das famílias na relação com a escola. Esse fato não foi negado até então, mesmo em pesquisas recentes.

Dentre os estudos sobre a família, destaca-se a Teoria da Reprodução de Bourdieu e Passeron, cujo enfoque central volta-se para o contexto sociocultural das famílias e sua influência na determinação das relações com a escola. Para tratar dessa relação, os autores utilizaram os conceitos de ethos de classe, capital cultural, habitus e estratégias parentais, os quais serão tomados, neste trabalho, como base do estudo.

Essa teoria representa um marco de renovação no âmbito das teorias de ação educacional, pois se distancia das correntes funcionalistas e marxistas no 
que diz respeito à ênfase na determinação dos processos escolares a partir das características da produção econômica capitalista (BOWLES e GENTIS, 1976; ALTHUSSER, 1970 e BAUDELOT e ESTABLET, 1971), na qual o papel da escola consiste em transmitir a ideologia dominante.

A excelência da obra de P. Bourdieu e J.-C. Passeron está em revelar a relação entre o sistema de ensino e a estrutura de classes sociais, na qual a educação é considerada como um instrumento de manutenção da desigualdade social, ou seja, como um mecanismo de reprodução social. Percebe-se, assim, que as instituições educacionais, embora favorecidas pelo papel tradicional de transmitir para as gerações a cultura herdada do passado, na verdade, desempenham uma função social ainda mais profunda e encoberta: colaboram para a reprodução da estrutura de classes sociais, intensificando a divisão cultural e de status entre elas.

\begin{abstract}
Para que sejam favorecidos os mais favorecidos e desfavorecidos os mais desfavorecidos, é necessário e suficiente que a escola ignore, no conteúdo do ensino transmitido, os métodos e técnicas de transmissão e, nos critérios de julgamento, as desigualdades culturais entre as crianças de diferentes classes sociais; dito de outra forma, tratando todos os alunos tão desiguais como são de fato, como iguais em direitos e em deveres, o sistema escolar é levado a dar de fato sua sanção às desigualdades iniciais diante da cultura. (BOURDIEU apud ANDRÉ, 1999, p. 15).
\end{abstract}

Constata-se, portanto, nessa teoria, que o processo de reprodução social direciona-se para a reprodução das relações de força entre as classes cujo objeto, segundo Silva (1992), não se constitui na diferenciação de bens materiais, mas nas desigualdades simbólicas, as quais servem de legitimação para as demais desigualdades. Para Bourdieu e Passeron, numa estrutura social estratificada, as classes sociais dominantes controlam os significados culturais mais valorizados, ao passo que os legitimam. E, quando inculcados por meio da edu- cação - processo de inculcação pedagógica -, tais significados normalmente são aceitos e respeitados pelos grupos subordinados na estrutura social. Dessa maneira, as relações de poder entre as classes sociais são intercedidas por significados simbólicos, nos quais a cultura, impregnada de sentido político, é uma autêntica expressão desse poder.

Nessa dimensão, Silva (1992) afirma que o êxito funcional da escola está no processo de exclusão cultural que realiza - o que acaba por contribuir para a reprodução das classes sociais. Para explicar esse processo de exclusão por qual passam as classes populares, Bourdieu e Passeron se ampararam nos conceitos de ethos de classe e capital cultural. Segundo eles, a família procura transmitir a seus filhos um ethos de classe, ou seja, “[...] um sistema de valores implícitos e profundamente interiorizados que contribui para definir, entre outras coisas, as atitudes face ao capital cultural e à instituição escolar" (BOURDIEU, 1998, p. 42).

\begin{abstract}
De maneira geral, as crianças e suas famílias se orientam sempre em referencia às forças que a determinam. Até mesmo quando suas escolhas thes parecem obedecer à inspiração irredutível do gosto ou da vocação, elas trazem a ação transfigurada das condições objetivas. Em outros termos, a estrutura das oportunidades objetivas de ascensão social e, mais precisamente, das oportunidades de ascensão pela escola, condicionam as atitudes frente à escola e à ascensão pela escola atitudes que contribuem, por uma parte determinante, para definir as oportunidades de se chegar à escola, de aderir a seus valores ou a suas normas e de nela ter êxito; de realizar, portanto, uma ascensão social - e isso por intermédio de esperanças subjetivas (partilhadas por todos os indivíduos definidos pelo mesmo futuro objetivo e reforçadas pelos apelos à ordem do grupo), que não são senão as oportunidades objetivas intuitivamente apreendidas e progressivamente interiorizadas. (BOURDIEU, 1998, p. 49)
\end{abstract}

Com isso, os autores enfatizam a autosseleção dos indivíduos, que se processa através da correlação existente entre "esperanças subjetivas e oportunidades objetivas" (BOURDIEU apud SWARTZ 1997, p. 44). 
Assim, as perspectivas que apresentam os pais diante da educação dos filhos são o resultado da sua experiência como indivíduo pertencente a um grupo cultural determinado. Destaca-se, porém, que esse processo de exclusão não acontece por imposição explícita ou violência física, mas pela ausência de condição de alguns vencerem a corrida meritocrática da carreira escolar, a qual é concebida como justa e igualitária.

É oportuno esclarecer que, por uma condição arbitrária, dada pela posição de força na relação entre as classes, a cultura dominante é definida como a cultura legítima, o que a transforma, por si mesma, em capital cultural, ou seja, em "competência lingüística e cultural socialmente herdada que facilita o desempenho escolar." (SWARTZ, 1997, p. 30).

A noção de capital cultural impôs-se [...] como uma hipótese para dar conta da desigualdade de desempenho escolar de crianças provenientes das diferentes classes sociais relacionando o 'sucesso escolar', ou seja, os benefícios específicos que as crianças das diferentes classes e frações de classe podem obter no mercado escolar à distribuição do capital cultural entre as classes e frações de classe. Este ponto de partida implica em uma ruptura com os pressupostos inerentes, tanto à visão comum que considera o sucesso ou fracasso escolar como efeito das 'aptidões' naturais, quanto às teorias do 'capital humano'. (BOURDIEU, 1998, p. 73).

Assim, confere-se valiosa vantagem ao possuidor desse capital junto às classes sociais, sendo que tais vantagens se configuram basicamente no domínio prático e informal da cultura e da linguagem, de um modo geral, no poder de abstração, no domínio da expressão escrita e falada, dentre outras. Assim, reflete-se: as crianças das classes subordinadas encontram-se à margem desse processo?

Para Bourdieu e Passeron, elas não estão alheias a tal situação. Contudo, a diferença consiste na inculcação a que são submetidas. Essa inculcação, ao não se referir a propriedades culturais da classe dominante, não apresenta valor no mercado do capital cultural. E a função da escola nesse processo, embora contribua para reforçar a inculcação e a transmissão cultural, é secundária, pois, efetivamente, sua função reside em legitimar as desigualdades produzidas no contexto da família, transmutando-as em diferenças nos esforços de aquisição da cultura escolar.

Diante desse quadro, Silva (1992) sinaliza para a essência do processo de reprodução social, o qual se encontra direcionado para a maneira como o capital cultural é transmitido entre as gerações. Entretanto, ressalta-se que essa transmissão não acontece de forma tranquila, visto ser o resultado de uma inculcação pedagógica da escola, que exerce sua "violência simbólica" .

Ressalta-se, porém, que, para que essa mesma transmissão seja eficaz, é necessário que as propriedades culturais transmitidas se transformem em disposições duradouras, ou seja, em habitus, “[...] o que só se realiza sob condição de uma longa imersão num ambiente em que estejam presentes esses itens culturais [...]" (SILVA, 1992, p. 33), no caso a família.

\begin{abstract}
O habitus é, portanto, o que faz com que seja possível reconhecer que somos da mesma grande escola, da mesma classe social e do mesmo meio [...] No fundo, o habitus é o princípio silencioso de cooptação e reconhecimento que opera as classificações, em primeiro lugar, escolares e depois sociais. (COULON, 1995, p. 151).
\end{abstract}

Nota-se que, como tal, o habitus configura-se como um gerador de estratégias de investimento educacional, ou seja, estratégias de reprodução de classe, por meio das quais os grupos tentam manter ou melhorar sua posição na estrutura das relações de classe, salvaguardando ou aumentando seu capital cultural. Para essa teoria, à escola cabe o papel de confirmação do habitus dominante, da estrutura interiorizada, limitando-se, assim, a "[...] usar um código de transmissão no qual apenas as crianças e os jovens da classe dominante, 
que já foram iniciados no ambiente da família, a permitir a continuação desses no jogo da cultura e a confirmar a exclusão dos filhos de pais das classes subordinadas" (SILVA, 1992, p. 18).

Nessa perspectiva, segundo os postulados da Teoria da Reprodução as famílias se diferenciam umas das outras pela estrutura e o volume do seu patrimônio (capitais) acumulado (background), que thes assegura uma posição na estrutura social, forjando ethos e habitus específicos que por sua vez geram estratégias expressas em práticas. As estratégias familiares refletem, portanto, um cálculo (que não é puramente racional) a partir das chances de ascensão que cada grupo é capaz de antever e de atrair para si. A escola como instituição que confere títulos legítimos e legitimadores representa possibilidades diferentes para cada grupo de agentes, ocupando um lugar mais ou menos central no projeto familiar e, consequentemente, mobilizando investimentos (reais e simbólicos) na escolarização dos filhos de acordo com sua importância na manutenção ou aquisição de privilégios de classe.

\section{CONCLUSÃO}

As Ciências Sociais e da Educação, dos anos 1960 aos anos 1980, ocupou-se basicamente com estudos voltados para a questão das desigualdades de acesso e de desempenho escolar, mostrando correlações estatísticas entre a origem social das famílias e o sucesso ou fracasso escolar dos alunos, numa perspectiva macroestrutural.

Só a partir dos anos 1980, depois de constatado o pouco conhecimento acumulado sobre os processos por meio dos quais se desenvolvem as relações família-escola, é que começaram a se desenvolver pesquisas que visavam a penetrar nos enigmas da socialização familiar e na sua relação com as trajetórias escolares das camadas sociais, em especial, das camadas populares ${ }^{8}$. Por isso, apesar de toda a contribuição trazida pela Teoria da Reprodução, cabe salientar que alguns autores the apontaram limites, dentre eles Coulon (1995). Numa análise crítica, esse autor se refere à onipresença do habitus da teoria de Bourdieu e Passeron, afirmando que o ator social de Bourdieu não é influenciado pelas diferentes aprendizagens a que é submetido, tendo seu destino traçado, então, pelo habitus inicial. Mas vê que deixa de ser considerada a intervenção consciente e voluntária do ator, não levando, assim, em conta suas estratégias pessoais.

Ainda como limitação dessa teoria, Petitat (1994) aponta que, apesar de ser dito que sua estrutura é supostamente universal e aplicável a qualquer ação pedagógica, existe a ressalva de que, durante o período de luta pela posição dominante, a legitimidade da autoridade pedagógica é questionada, assim como a própria classe dominante, uma vez que a legitimação das instituições pedagógicas nunca é completa, partindo-se do princípio das contradições na sociedade capitalista. Dito de outra forma, sua perspectiva de reprodução estrutural elimina a consideração da contradição como um gerador de ação humana e transformação social. Esse autor afirma, ainda, que tais considerações vêm apenas limitar a área de aplicação da teoria da violência simbólica, e não negar sua validade.

Também os autores Nogueira, Romanelli e Zago (2000), na obra Família e Escola: trajetórias de escolarização em camadas médias e populares apontam a relevância dada pela Teoria da Reprodução aos aspectos macroestruturais da relação entre família e escola, ao tempo que omitiram os fatores microestruturais concernentes a essa relação. Com isso, Bourdieu e Passeron não tomaram em conta os processos e as dinâmicas intrafami-

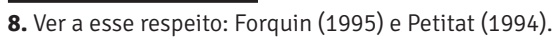


liares, as práticas socializatórias e as estratégias educativas internas ao microcosmo familiar, cujos elementos, analisados intrinsecamente, põem sob questionamento o pressuposto da atuação positiva do capital cultural e escolar da família nos resultados escolares dos descendentes.

Em torno dessa problemática, Swartz (1997) mostra que, embora essa abordagem ilumine os mecanismos culturais e pedagógicos mais sutis que contribuem para a permanência da estratificação social, ela também omite da análise a relação da escolarização com o Estado e o processo de trabalho.

Nessa ótica interpretativa, pode-se concluir que as práticas educativas parentais, mais especificamente as relações que os pais estabelecem com a escola dos filhos, não é algo simples de ser analisado. Sua complexidade parte da ideia que se tem sobre família como um conjunto de complexas relações, composta de indivíduos diferenciados por idade e, talvez por sexo, que se relacionam diariamente, dando origem a uma dinâmica e complexa rede de sentimentos. Dessa maneira, ela não se configura como uma simples soma de indivíduos, mas como um conjunto vivo, contraditório e cambiante de pessoas com individualidade e personalidade próprias.

Assim, ao pretender analisar as práticas educativas parentais, é preciso considerar dentre outros fatores, não só a influência a que estão sujeitas, dada as transformações ocorridas no seio das famílias contemporâneas, como também as dinâmicas internas dessas famílias, buscando perceber a capacidade de ação dos sujeitos. De tal modo, as práticas educativas não devem ser consideradas apenas pelo aspecto do capital cultural que é concernente aos vários modelos de família.

Portanto, torna-se imprescindível direcionar os estudos para as novas configurações familiares, como forma de investigar a família distante das categorias clássicas de parentesco e aliança, sobretudo porque a construção de uma sociedade inclusiva exige o reconhecimento da diversidade social como legítima, como também demanda mudanças de ideias e de práticas construídas ao longo dos tempos. Assim, as famílias devem ser tomadas como um componente importante na viabilização da proposta de educação para todos. Torna-se então, fundamental que se invista na orientação e no apoio às famílias para que esta possa cumprir melhor com o seu papel educativo junto a seus filhos.

\section{REFERÊNCIAS}

ANDRÉ, Marli. Pedagogias das Diferenças na Sala de Aula. Campinas, SP: Papirus, 1999, 152 p.

BOURDIEU, P. A Escola Conservadora: as desigualdades frente à escola e a cultura. In: NOGUEIRA, A. L.; CATANI, A.(Orgs.) Escritos de Educação. Petrópolis: Vozes, 1998, p.39-64.

BOURDIEU, P. Sistemas de Ensino e Sistemas de Pensamento. In: Economia das Trocas Simbólicas. São Paulo: Perspectiva, 1998.

BOURDIEU, P. Os Três estados do Capital Cultural. In: NOGUEIRA, A. L.; CATANI, A.(Orgs.) Escritos de Educação. Petrópolis: Vozes, 1998, p.71-79.

BOURDIEU, P.; PASSERON, J-C. A Reprodução: elementos para uma teoria do ensino. Tradução de Reynaldo Bairão. 2.ed. Rio de Janeiro, RJ: Francisco Alves, 1982, 237p.

BRUSCHINI, Cristina. Teoria Crítica da Família. In: NOGUEIRA, V. A Infância e Violência Doméstica: fronteiras do conhecimento. São Paulo: Cortez, 1993, 334p.

CASTER, B; MCGOLDRICK, M. et al. As mudanças no ciclo de vida familiar: uma estrutura para a terapia familiar. Porto Alegre: Artes Médicas, 1995, 510p. 
COULON, Alain. Reprodução e Filiação. In: Etnometodologia e Educação. Petrópolis, R.J: Vozes, 1995, p.149-166.

FORQUIN, J. C. (org). Sociologia da Educação: dez anos de pesquisa. Tradução de Guilherme João de F. Teixeira. Petrópolis, RJ: Vozes, 1995.

GRZYBOWSKI, Luciana Suarez. Famílias monoparentais: mulheres divorciadas chefes de família. In: WAGNER, Adriana (Coord.). Família em cena: tramas, dramas, e transformações. Petrópolis: Vozes, 2002, cap.2, p.39-53.

MARINI, Fabiana; MELLO, R. Rodrigues de. Relação entre a Escola e Família de Classes Populares: desconhecimento e desencontro. UFSCAR, 2000. 9 p. Disponível em: <Projet fa écolel0606t.htm>. Acesso em: 5 out. 2000.

NOGUEIRA, Maria Alice. ROMANELLI, Geraldo; ZAGO, Nadir. (orgs). Família e Escola: trajetórias de escolarização em camadas médias e populares. Petrópolis, RJ: Vozes, 2000,183p.

PETITAT, André. Produção da Escola/ Produção da Sociedade. Porto Alegre: Artes Médicas, 1994, 268p.

REGO, C. T. Vigotski: uma perspectiva histórico-cultural da educação. 11.ed. Petrópolis: Vozes, 1995, 138p.
SARTI, Cyntia. Algumas questões sobre família e políticas sociais. In: JAQUET, C.; FIALHO, L. C. (Orgs.). Família em mudança. São Paulo: Companhia Ilimitada, 2004, p.193-213.

SEGALEN, Martine. Sociologia da família. Lisboa: Terramar, 1996.

SILVA, Tomáz Tadeu. A dialética de uma tradição: produção e reprodução em Sociologia da Educação. In: $\mathbf{0}$ que Produz e o que Reproduz em Educação. Porto Alegre: Artes Médicas, 1992, parte I, p.13-71.

SINGLY, François. Sociologia da Família Contemporânea. Tradução: Clarice Ehlers Peixoto. Rio de Janeiro: FGV, 2007.

SWARTZ, David. Pierre Bourdieu: a transmissão cultural da desigualdade social. In: PATTO, Maria Helena Souza (org.). Introdução à Psicologia Escolar. 3.ed. São Paulo: Casa do Psicólogo, 1997, cap. 3, p.35-49.

WAGNER, Adriana (Coord.). Família em cena: tramas, dramas, e transformações. Petrópolis: Vozes, 2002.188p. 
1. Biomédico. Assessor de qualidade e biossegurança no Centro de Hemoterapia de Sergipe - Hemose.E-mail: weber.teles@fsph.se.gov.br

\section{Graduanda de Enfermagem da Universidade Tiradentes. E-mail:} hozanapatricio@gmail.com

3. Biomédico no Centro de Hemoterapia de Sergipe - Hemose. E-mail: kleber.willer@hotmail.com

4. Doutor em Parasitologia, docente permanente do Curso de Mestrado em Saúde e Ambiente da Universidade Tiradentes. E-mail: rrmadi@ gmail.com

5. Doutora em Parasitologia, docente permanente do Curso de Mestrado em Saúde e Ambiente da Universidade Tiradentes. E-mail: veronica_sierpe@hotmail.com

Recebido em: 29 de Abril de 2014 Avaliado em: 28 de Maio de 2014 Aceito em: 7 de Julho de 2014
6. Doutora em Parasitologia, docente permanente do Curso de Mestrado em Saúde e Ambiente da Universidade Tiradentes. E-mail: claudiamouramelo@hotmail.com 